protons. Even so, the time taken to yield significant results will be an order of magnitude less than that in which these were accessible only three years ago-a telling proof of how the existence of a gigantic proton accelerator is not a substitute for, but rather an incentive to, clever design.

\section{Locusts Come and Go}

THE writers of the Bible would have learned much about the upsurges and recessions in the desert locust plague from a historical survey published by the Antilocust Research Centre (Anti-Locust Memoir No. 8) in London. The insect (Schistocerca gregaria) covers most of Africa north of the Equator, and much of Western Asia-a total of twenty-nine million square kilometres in more than fifty countries. But locusts are always on the move, alone and in swarms. Breeding takes place in three principal areas at times which are closely associated with the local rainy seasons. In the spring (March to June), locusts breed in northwest and northern Africa and farther east as far as Pakistan. Locusts breed in the summer, between August and September, south of the Sahara and through Southern Arabia to Pakistan. The third winter breeding zone (October to January) covers East Africa and the Red Sea coast.

Between one and three months after the onset of egg laying, the parent generation dies off, the young locusts pass through the hopper stage and develop wings, gather into swarms and migrate to other breeding areas. The spring swarms from North-west Africa and the Arabian Peninsula move southwards and eastwards into the summer breeding zone where they mature and lay eggs when the rains come. The swarms of the summer generation migrate to the north into the spring breeding zone, where they are joined by swarms of the winter generation also moving north.

When conditions in two complementary breeding zones favour rapid maturation and gregarization a major plague can be set in train. The migration of a large swarm to a second suitable breeding area can so increase the numbers as to produce a plague such as the four which have been documented in this century. Climate is probably the principal influence favouring gregarization. In Oman in October 1948, a tropical cyclone probably concentrated locusts in an area made suitable for breeding by heavy rains. Rainfall permits lush growth of the plants on which the locusts lay their eggs and on which the hoppers can gather; and if eggs are laid close together, the hoppers are more likely to form a band and move together. If breeding should be possible after the maturation of adults, further generations are possible and the increase in density may result in gregarization.

Adverse climatic conditions are also frequently responsible for the decline of locust plagues. In the Somali Peninsula, after the partial failure of the short rains in 1955, many swarms of locusts were unable to find suitable breeding sites and many eggs were lost. Combined with heavy predation on the hoppers, this resulted in a recession of the plague until 1957. Predators also help to keep plagues in check, and there are insect and frugal parasites which can reduce numbers considerably.

It is clear from the survey that plagues always arise in the same general areas, where conditions favour an increase in density and gregarization. These areas could, as the report suggests, be watched, by means of combined ground and aerial reconnaissance, for the build-up of swarms and with the aim of preventing the development of plagues.

\section{Alarm about Aflatoxin}

ALARM was expressed at a recent meeting in Rome of the Food and Agriculture Organization of the United Nations about the amount of aflatoxin in peanuts and other protein supplements. Aflatoxin is produced by a mould called Aspergillus flavus on common foods such as peanuts, maize and even rice, if they are kept under bad storage conditions, and it is known to be carcinogenic. The maximum concentration of aflatoxin which is permitted was laid down in August last by a joint advisory group from the Food and Agriculture Organization and the World Health Organization, which took into account the urgent need to provide extra protein in some parts of the world, and established a level of $30 \mu \mathrm{g} / \mathrm{kg}$ of foodstuffs. Clearly the group would have preferred a lower figure, but felt that the danger of malnutrition was greater than the danger that aflatoxin would produce liver cancer in man.

It has been known for some time that aflatoxin produces liver cancer in animals such as pigs, cows, rats, monkeys and turkeys (Nature, 192, 1095; 1961). What is not known is the extent to which this effect may be duplicated in man, but Dr. Bruce Nichol of the FAO said that it was suspected that some of the cases of liver cancer in countries producing ground-nuts could be attributed to aflatoxin. Dr. René Truhaut, Director of the Centre de Recherches Toxicologiques in Paris, said that he was not satisfied with the level, or with the means of establishing it. Aflatoxin, he said, was 1,000 to 1,500 times more virulent than butter yellow, a butter additive which is prohibited all over the world. The toxic level has been established by experiments with monkeys, but he said that the tragic cases of food poisoning in Morocco, when people were crippled after consuming olive oil mixed with mineral oils, had shown how dangerous it may be to extend results obtained with monkeys to human beings. Monkeys had proved completely immune to the toxic agent in the oil-orthotricresylphosphate.

Dr. P. C. Spensley of the Tropical Products Institute in London was more reassuring; he said that new methods of peanut harvesting, processing and storage had considerably reduced the affatoxin content in recent years. In London last week he added that long term experiments with animals should continue to be carried out. So far as people are concerned, the new International Agency for Research in Cancer was conducting a statistical survey with WHO in countries where liver cancer is common. Dr. Spcnsley said that primary liver cancer is a tropical disease, so that there is clearly a correlation between the disease and climate; whether there is in fact a correlation between the disease and the presence of aflatoxin in food should be clear from the statistical survey.

\section{Myxomatosis in Australia}

A NEw look at myxoma virus and its use in the control of rabbit populations is to be found in No. 56 of the quarterly review of Rural Research in C.S.I.R.O. The virus was first successfully introduced from the United States into the Australian rabbit population in 1950. 